\title{
Investigation of Dc-Conductivity and Morphology of PMMA/PANI Composite
}

\author{
M.K. Panigrahi ${ }^{1,}{ }^{*}$
}

${ }^{1}$ PG Department Materials Science, Maharaja Sriram Chandra Bhanja Deo University, Keonjhar Campus, Odisha, India. ${ }^{*}$ Corresponding author Email: muktikanta2@gmail.com

DOI: https://doi.org/10.34256/irjmt2128

Received: 08-03-2021, Revised: 19-03-2021, Accepted: 20-03-2021, Published: 21-03-2021

Abstract: Various inorganic acid doped PMMA/PANI composite are prepared by in-situ polymerization technique. Morphology, room temperature (RT) conductivity and DC-conductivity with temperature variation (77-300 K) are analyzed by scanning electron microscopy (SEM) and linear four probe technique, respectively. Fibril structures with different diameter are observed in doped PMMA/PANI composite, whereas smooth texture is found in PMMA polymer film. Room temperature DC conductivity is found $0.1497 \times 10^{-2} \mathrm{~S} / \mathrm{cm}$ for $\mathrm{H}_{2} \mathrm{SO}_{4}$-and $0.309 \times 10^{-3} \mathrm{~S} / \mathrm{cm}$ for $\mathrm{H}_{3} \mathrm{PO}_{4}$, $0.244 \times 10^{-3} \mathrm{~S} / \mathrm{cm}$ for $\mathrm{HCl}$-doped conductive composite, respectively. Temperature dependent DC Conductivity is measured and it behaves like semiconductor.

Keywords: PMMA, PANI-ES, Dopant, Conductivity, Organic semiconductor.

\section{Introduction}

It is well known that intrinsic conducting polymers (ICPs) have considered much more scientific community interest over the last few years due to potential commercial applications in different fields such as electrochromic devices, light emitting diodes supercapacitors, rechargeable batteries, sensors, corrosion inhibitors and artificial muscles [1-7]. Polyaniline (PANI) is a member of ICPs family. It has both good thermal and environmental stability coupled with easy processable and doping-dedoping mechanism [8]. In spite of above advantages, PANI has poor processability due to insolubility and brittleness limits for its commercial applications. PANI can be made more processable in the composite form with electroactive polymer which is act as stabilizer [9]. Now a day, a variety of PANI composite have been studied using many types of synthetic electroactive polymers such as poly (methyl methacrylate), polyvinyl chloride, polystyrene, and polyurethane [10-13]. Poly ( $\alpha$-hydroxy acid), polylactide (PLA), polyglycolide and their copolymers have been widely used in tissue engineering because of their good biocompatibility, mechanical properties, bioresorable degradation products and adjustable degradation rate [14-16]. The efficient polymerization of aniline was achieved only in acidic medium. A variety of inorganic acids at same concentration have been used in the synthesis of PANI; resulting PANI-salts, protonated with various acids, differs in solubility, conductivity and stability [17]. Till now, it is difficult to understand the mechanism of its structural, thermal, magnetic and electrical properties of conducting polyaniline. So a lot of research has been devoted. Jing Li and co-workers [18] proposed a variable range of hoping (VRH) model which described the transport mechanism of $\mathrm{HCl}$-doped and DBSA-doped PANI. Atul Kapil et al [19] analyzed transport mechanism by Arrhenius model, variable range hoping (VRH) model and Kivelson model over wide range of temperature 30300K. Nadra Bohli [20] suggested the conduction mechanism of PANI organic film in the temperature range $100-300 \mathrm{~K}$. Y. Long and co-workers used variable range hoping (VRH) and charge energy limited tunneling (CELT) models to explain conductive property of PANI [21].

In this work, PMMA/PANI composite doped with different inorganic acid i.e., $\mathrm{HCl}, \mathrm{H}_{2} \mathrm{SO}_{4}$ and $\mathrm{H}_{3} \mathrm{PO}_{4}$ are prepared by oxidation-polymerization process using aniline, PMMA film, ammonium persulphate (APS) with appropriate amounts of water as precursors. DC conductivity $(\sigma)$ is estimated in both low- and roomtemperature. Morphological analyses of composites are explored. 


\section{Experimental Details}

\subsection{Chemicals and Materials}

Laboratory grade aniline, ammonium persulphate (APS) $\left.\left(\mathrm{NH}_{4}\right)_{2} \mathrm{~S}_{2} \mathrm{O}_{8}\right)$ sulphuric acid $\left(\mathrm{H}_{2} \mathrm{SO}_{4}\right)$, ortho-phosphoric acid $\left(\mathrm{H}_{3} \mathrm{PO}_{4}\right)$, chloroform $\left(\mathrm{CHCl}_{3}\right)$ diethyl ether $\left(\left(\mathrm{C}_{2} \mathrm{H}_{5}\right)_{2} \mathrm{O}\right)$ are purchased from Merck, India. Deionized water is used during the preparation of composite. Poly (methylmethacrylate) (PMMA) is used as base materials.

\subsection{PMMA/PANI Composite Preparation}

$\mathrm{CHCl}_{3}$ solvent is poured into a beaker $(100 \mathrm{ml})$, which is contained PMMA Polymer. The mixtures are stirred for $3 \mathrm{~h}$ and a soluble mass is formed. The mass is cast into ptridish (diameter $10 \mathrm{~cm}$ ). Films are formed after solvent evaporation. It is removed from ptridish and is cut into small pieces $(1.5 \mathrm{~cm} \times 1.5 \mathrm{~cm})$ i.e., square sized. Thickness of film is $0.2 \mathrm{~cm}$.

PMMA /PANI composite are prepared by chemical-oxidation polymerization process from aniline monomer coupled with base materials at room temperature. Two type of solution is prepared during the composite preparation. Former one is monomer solution
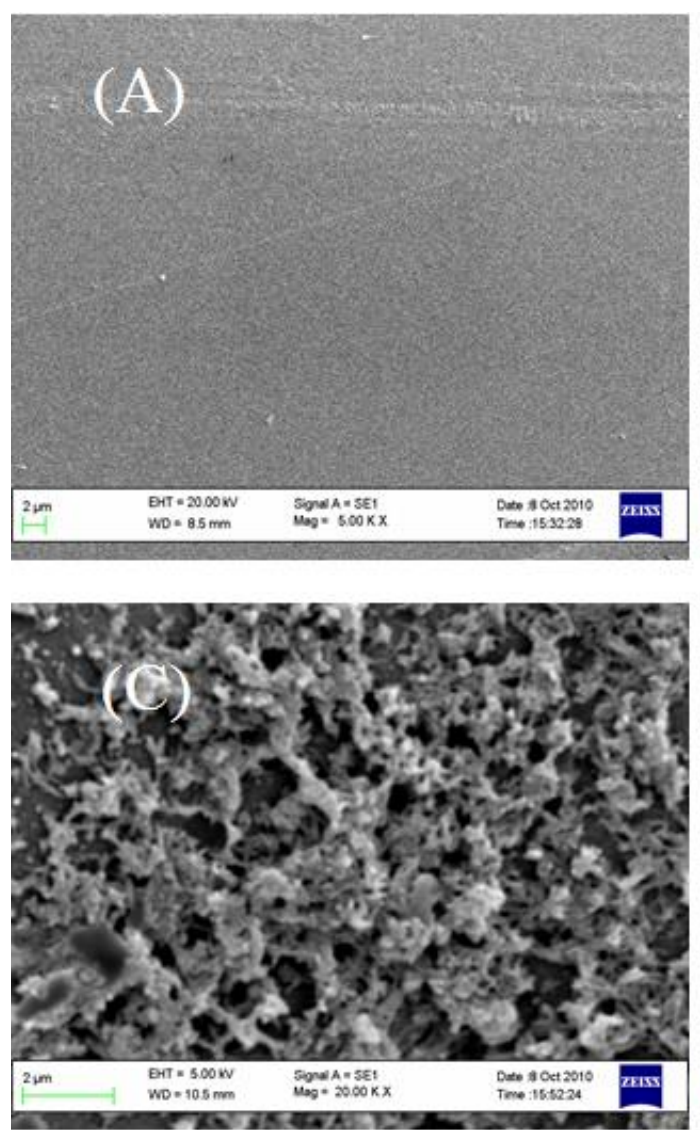
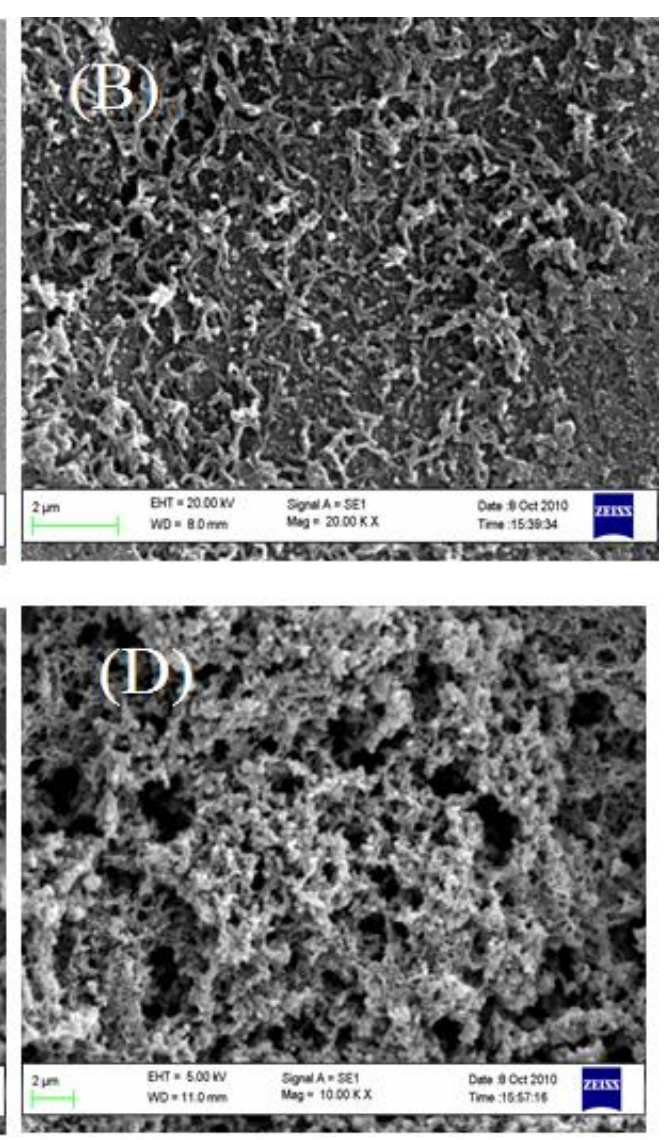

and later one is oxidant solution. During the preparation of monomer solution, $105 \mathrm{ml}$ of 1 (M) $\mathrm{H}_{2} \mathrm{SO}_{4}$ solution with $3 \mathrm{~mL}$ of aniline is taken and square sized PMMA films are dipped into the solution. The solution is stirred continuously $(10 \mathrm{~h})$ in a magnetic stirrer $(800 \mathrm{rpm})$. Oxidant solution is prepared using $7.47 \mathrm{~g}$ ammonium persulphate and $60 \mathrm{~mL}$ of 1 (M) $\mathrm{H}_{2} \mathrm{SO}_{4}$ solution. It is added drop wise to the monomer solution with continuous stirring. The polymerization process is carried out. The color of PMMA film(s) is becomes light green to dark green. The reaction mixture is maintained under stirring for $10 \mathrm{~h}$. The resulting composite is washed with deionized water several times. The wet PMMA/PANI films are dried in heating oven in a $60^{\circ} \mathrm{C}$ for 6 h [22]. For comparison study, doped- $\mathrm{H}_{3} \mathrm{PO}_{4}$ PMMA/PANI composite are also prepared under similar conditions.

\section{Characterization Techniques}

Surface morphology of PMMA polymer film, PANI, and PMMA/PANI composite are analyzed by scanning electron microscopy (Carl Zeiss Supra 40). Samples are coated with gold before the measurement.

Figure $1 \mathrm{FESEM}$ images of PMMA polymer film (A), $1 \mathrm{M} \mathrm{HCl}$ doped PMMA PANI composite (B), $1 \mathrm{M} \mathrm{H}_{3} \mathrm{PO}_{4}$ doped PMMA PANI composite (C), and $1 \mathrm{M} \mathrm{H}_{2} \mathrm{SO}_{4}$ doped PMMA PANI composite (D) 


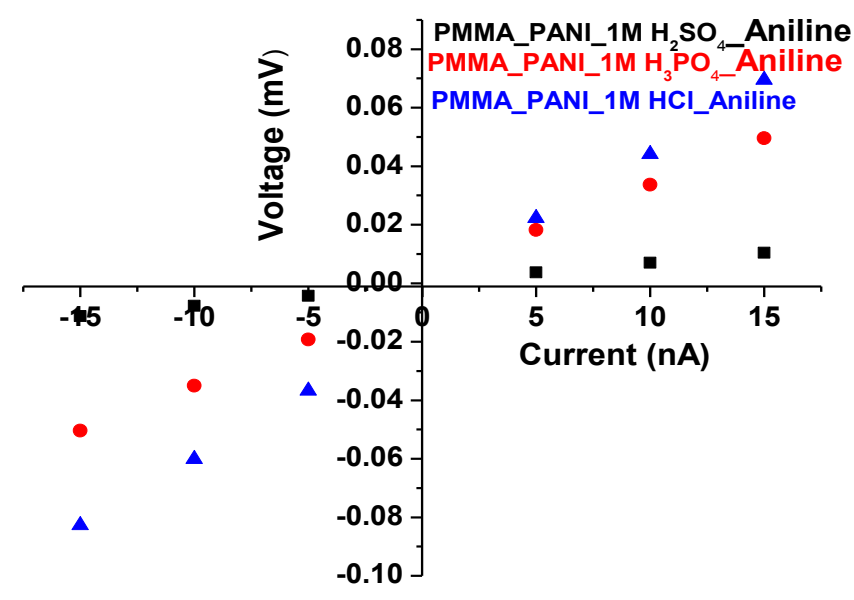

Figure $2 \mathrm{I}-\mathrm{V}$ characteristics of PMMA/PANI Composite $\left(1 \mathrm{M} \mathrm{H}_{2} \mathrm{SO}_{4}\right)(\mathrm{A})$, PMMA/PANI Composite $\left(1 \mathrm{M} \mathrm{H}_{3} \mathrm{PO}_{4}\right)(\mathrm{B})$, PMMA/PANI Composite (1 $\mathrm{M} \mathrm{HCl}$ (C)

Table 1 Room Temperature DC Conductivity of doped PMMA/PANI Composite

\begin{tabular}{|l|l|}
\hline Doped PMMA/PANI Composite & Conductivity (S/cm) \\
\hline $1 \mathrm{M} \mathrm{HCI}$ PMMA/PANI Composite & $0.244 \times 10^{-3}$ \\
\hline $1 \mathrm{M} \mathrm{H}_{2} \mathrm{SO}_{4} \mathrm{PMMA}$ PANI Composite & $0.1497 \times 10^{-2}$ \\
\hline $1 \mathrm{M} \mathrm{H}_{3} \mathrm{PO}_{4} \mathrm{PMMA}^{-} \mathrm{PANI}$ Composite & $0.309 \times 10^{-3}$ \\
\hline
\end{tabular}

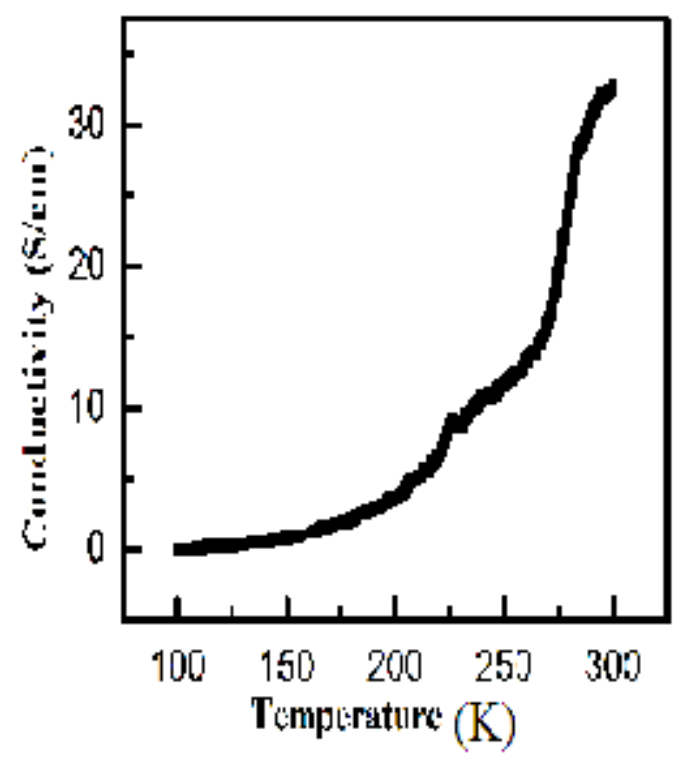

Figure 3 Temperature dependent DC Conductivity

DC-conductivity of the conducting samples (at room temperature and low to high temperature) is measured using a linear four-probe technique. DCconductivity are calculated using the relation $\rho=2 \pi S(V / I)$ where $S$ is the probe spacing $(\mathrm{mm})$, ' $l$ ' is the supplied current $(\mathrm{nA})$ and ' $\mathrm{V}$ ' is the corresponding voltage $(\mathrm{mV})$. The conductivity $(\sigma)$ is calculated using the expression $\sigma=1 / \rho$.

\section{Results and Discussion}

SEM images for pure PMMA polymer film and doped PMMA/PANI Composites are shown in Figure 1. Smooth texture is observed in Figure $1 \mathrm{~A}$, whereas fibrous structures are showed in all doped PMMA/PANI Composites. Three dopants viz., $\mathrm{HCl}, \mathrm{H}_{2} \mathrm{SO}_{4}$ and $\mathrm{H}_{3} \mathrm{PO}_{4}$ are used to prepare doped PMMA/PANI Composites. It is also found that size and formation probability of PANI is strongly dependent on dopant strength, structure and 
reaction conditions. Moreover, the diameter size of PANI nano-fibrous is affected by dopant structure. Average (av.) diameters of PMMA/PANI composites are found to be $178 \mathrm{~nm}, 152 \mathrm{~nm}$, and $165 \mathrm{~nm}$, respectively. The diameter is related to aspect ratio i.e., surface area/volume. The surface area of nanofibers increases as the average diameter of nanofibers decreases. it could be important, particularly for gas sensor application.

I-V Characteristics of $\mathrm{HCl}-, \mathrm{H}_{2} \mathrm{SO}_{4}$ - and $\mathrm{H}_{3} \mathrm{PO}_{4}$ doped PMMA/PANI composites are plotted and is shown in Figure 2. In Figure 2, voltage $(\mathrm{mV})$ is linearly related with current $(n A)$, which is passes through origin. This is the indication of ohmic behaviour $[\mathrm{xxx}]$. DC conductivity of doped composites is presented in Table 1. It is cleared from the Table 1 that the $\mathrm{DC}$ conductivity of $\mathrm{H}_{2} \mathrm{SO}_{4}$ doped PMMA/PANI composite showed $0.1497 \times 10^{-2}$ $\mathrm{S} / \mathrm{cm}$ higher than other doped PMMA/PANI composites.

$\mathrm{H}_{2} \mathrm{SO}_{4}$ dopant has bigger size counter ion and higher strength than other two dopants. Therefore, $\mathrm{H}_{2} \mathrm{SO}_{4}$ exert less force against ordering and closing of PANI chains leading to higher compactness of PANI chains. The compactness is a favorable factor for intermolecular mobility of charged species along the chain and some extent inter molecular hopping because of better and closer packing and hence, higher conductivity than the latter's [22, 23].

Figure 3 shows the temperature dependence DC Conductivity of $\mathrm{H}_{2} \mathrm{SO}_{4-}$ doped PMMA/PANI composite.

It is evident from the Figure 3 that the conductivity increases with increase in temperature. The composite represent temperature dependent conductivity. This behaviour is similar to a semiconductor. Hence, the composite is called organic semiconductor.

\section{Conclusions}

PMMA/PANI composite uses $\mathrm{HCl}, \mathrm{H}_{2} \mathrm{SO}_{4}$ and $\mathrm{H}_{3} \mathrm{PO}_{4}$ as dopants are prepared by insitu polymerization technique. The entire prepared composite are shown nonofibriles structure having average diameter $178 \mathrm{~nm}$ for $\mathrm{HCl}$ doped PMMA /PANI composite, $153 \mathrm{~nm}$ for $\mathrm{H}_{2} \mathrm{SO}_{4}$-doped PMMA /PANI composite, and average diameter $163 \mathrm{~nm}$ for $\mathrm{H}_{3} \mathrm{PO}_{4}$-doped PMMA /PANI composite. As prepared conducting composites show ohmic behaviour at room temperature. Highest room temperature DC conductivity is found to be $0.1497 \times 10^{-}$ $2 \mathrm{~S} / \mathrm{cm}$ for $\mathrm{H}_{2} \mathrm{SO}_{4}$-doped PMMA/PANI composite. Temperature dependent of conductivity indicate the organic semiconductor.

\section{References}

[1] J.H. Burroughes, D.D.C. Bradley, A.R. Brown, R.N. Marks, K. Mackay, R.H. Friend, P.L. Burns \& A.B. Holmes, Light-emitting Diodes Based on Conjugated Polymers, Nature, 347 (1990) 539-541. https://doi.org/10.1038/347539a0

[2] E. Frackowiak, V. Khomenko, K. Jurewicz, K. Lota, F. Beguin, Supercapacitors Based on Conducting Polymers/Nanotubes Composites, Journal of Power Sources, $153 \quad$ (2006) 413-418. https://doi.org/10.1016/j.jpowsour.2005.05.030

[3] C. Conn, S. Sestak, A.T. Baker, J. Unsworth, A Polyaniline-Based Selective Hydrogen Sensor, Electroanalysis, 10(1998) 1137-1141. https://doi.org/10.1002/(SICI)15214109(199811)10:16\%3C1137::AIDELAN1137\%3E3.0.CO;2-1

[4] R. Abdelkader, H. Amine, B. Mohammed, Thermally Stable Forms of Pure Polyaniline Catalyzed by Acidexchanged Montmorillonite Clay called Maghnite$\mathrm{H}+$ as an Effective Catalyst, International Journal of polymer science, $2012 \quad 1-7$. https://doi.org/10.1155/2012/846710

[5] S. Yang, E. Ruckenstein, Processable Conductive Composites of Polyaniline/Poly (alkyl methacrylate) Prepared via an Emulsion Method, Synthetic Metals, 59(1993) 1-12. https://doi.org/10.1016/03796779(93)91152-R

[6] V. Singh, S. Mohan, G. Singh, P.C. Pandey, R. Prakash, Synthesis and Characterization of Polyaniline-carboxylated PVC Composites: Application in Development of Ammonia Sensor, Sensors and Actuators B: Chemical 132(2008) 99106. https://doi.org/10.1016/i.snb.2008.01.007

[7] M. Okubo, S. Fujii, H. Minami, Production of Electrically Conductive, Core-shell Polystyrene/Polyaniline Composite Particles by Chemically Oxidative Seeded Dispersion Polymerization, Colloid and Polymer Science, 279 (2001)

139-145. https://doi.org/10.1007/s003960000405

[8] M. Spirkova, J. Stejskal, O. Quadrat, Electrically Anisotropic Polyaniline-Polyurethane Composites, Synthetic Metals, 102 (1999) 1264-1265. https://doi.org/10.1016/S0379-6779(98)01461-1

[9] A. Aleshin, R. Kiebooms, R. Menon, A.J. Heeger, Electronic Transport in Doped Poly (3,4ethylenedioxythiophene) Near the Metal-Insulator Transition, Synthetic Metals, 90(1997) 61-68. https://doi.org/10.1016/S0379-6779(97)81227-1 
[10] B.I. Shklovskii, and A.L. Efros, (1984), Electronic Properties of Doped Semiconductors, Springer, Berlin. https://doi.org/10.1007/978-3-662-02403-4

[11] Y.Z. Long, Z.H. Yin, Z.J. Chen, Low-Temperature Magnetoresistance Studies on Composite Films of Conducting Polymer and Multiwalled Carbon Nanotubes, Journal of Physical Chemistry C, 112 (2008)

11507-11512. https://doi.org/10.1021/ip709872k

[12] L. Zuppiroli, M.N. Bussac, S. Paschen, O. Chauvet, L. Forro, Hopping in Disordered Conducting Polymers, Physical Review B, 50 (1994) 5196-5203. https://doi.org/10.1103/PhysRevB.50.5196

[13] J. Li, K. Fang, H. Qiu, S. Li, W. Mao, Micromorphology and Electrical Property of the $\mathrm{HCl}$ doped and DBSA-doped Polyaniline, Synthetic Metals, $\quad 142 \quad$ (2004) 107-111. https://doi.org/10.1016/i.synthmet.2003.08.014

[14] A. Kapil, M. Taunk, S. Chand, Preparation and Charge Transport Studies of Chemically Synthesized Polyaniline, Journal of Materials Science: Materials in Electronics, 21 (2010) 399404. https://doi.org/10.1007/s10854-009-9931-2

[15] M. Reghu, C.O. Yoon, D. Moses, P. Smith, A.J. Heeger, and Y. Cao, Magnetoresistance in Polyaniline Networks Near the Percolation Threshold, Synthetic Metals, 69 (1995) 271-272. https://doi.org/10.1016/0379-6779(94)02446-6

[16] J.C. Clark, G.G. Ihas, A.J. Rafanello, M.W. Meisel, M. Reghu C.O. Yoon, Y. Cao, A.J. Heeger, Resistivity and Magnetoresistance of Metallic Polyaniline and Polypyrrole at Millikelvin Temperatures, Synthetic Metals, 69 (1995) 215-216. https://doi.org/10.1016/0379-6779(94)02421-T

[17] Y. Long, Z. Chen, X. Zhang, J. Zhang, Z. Liu, Synthesis and Electrical Properties of Carbon Nanotube Polyaniline Composites, Applied Physics Letters, $\quad 85 \quad$ (2004) 1796-1798. https://doi.org/10.1063/1.1786370

[18] C.S.S. Sangeeth, P. Jiménez, A.M. Benito, W.K. Maser, R. Menon, Charge Transport Properties of Water Dispersible Multiwall Carbon NanotubePolyaniline Composites, Journal of Applied Physics, 107 (2010) 103719-103723. https://doi.org/10.1063/1.3374628

[19] T.F. Abou-Elazab, M.D. Migahed, H. Park, Y.W. Park, P. MacNeillis, T. Rabenau, Magnetoresistance of Polypyrrole and Polyacetylene, Synthetic Metals, 76 (1996) 281-284. https://doi.org/10.1016/0379$\underline{6779(95) 03471-U}$
[20] J.M. Mativetsky, W.R. Datars, Morphology and Electrical Properties of Template-synthesized Polypyrrole Nanocylinder, Physica B: Condensed Matter, $324 \quad$ (2002) 191-204. https://doi.org/10.1016/S0921-4526(02)01297-8

[21] J.J. Langer, R. Krzyminiewski, Z. Krucznski, T. Gibinski, I. Czajkowski, G. Framski, EPR and Electrical Conductivity in Microporous Polyaniline, Synthetic Metals, 122 (2001) 359-362. https://doi.org/10.1016/S0379-6779(00)00362-3

[22] J. Li, K. Fang, H. Qiu, S. Li, W.J. Mao, Micromorphology and Electrical Property of the $\mathrm{HCl}$ doped and DBSA-doped Polyaniline, Synthetic Metals, $\quad 142 \quad$ (2004) 107-111. https://doi.org/10.1016/j.synthmet.2003.08.014

[23] G. Chakraborty, K. Gupta, A.K. Meikap, P.C. Jana, Direct Current Electrical Transport and Magneto Transport Properties of Polyaniline Nanocomposites, Journal of Physical Science, 14 (2010) 207-218.

\section{Acknowledgement}

The author conveys their sincere thanks to GIET, Gunupur, Rayagada, Odisha, India for providing Lab facilities to do the research work. The author is also like to thank the CRF, IIT Kharagpur for their providing testing facilities.

\section{Funding}

No funding was received for conducting this study.

\section{Conflict of interest}

The Author has no conflicts of interest to declare that they are relevant to the content of this article.

\section{About the License}

(C) The author 2021. The text of this article is open access and licensed under a Creative Commons Attribution 4.0 International License

\section{Cite this Article}

M.K. Panigrahi, Investigation of Dc-Conductivity and Morphology of PMMA/PANI Composite, International Research Journal of Multidisciplinary Technovation, 3(2) (2021) 49-53. DOI: https://doi.org/10.34256/irjmt2128 